\title{
Hematodinium infection seasonality in the Firth of Clyde (Scotland) Nephrops norvegicus population: a re-evaluation
}

\author{
N. D. Beevers ${ }^{1, *}$, E. Kilbride ${ }^{1}$, R. J. A. Atkinson ${ }^{2}$, D. M. Neil ${ }^{1}$ \\ ${ }^{1}$ Institute of Biodiversity, Animal Health and Comparative Medicine, College of Medical, Veterinary and Life Sciences, \\ University of Glasgow, Glasgow G12 8QQ, UK \\ ${ }^{2}$ University Biological Marine Station, Millport, Isle of Cumbrae KA28 0EG, UK
}

\begin{abstract}
Hematodinium infections in Norway lobster Nephrops norvegicus from the Clyde Sea area (CSA) population, Scotland, UK, have previously been undetected in summer. This study aimed to establish if the CSA is actually devoid of infected $N$. norvegicus in this season. Two PCR assays, an ELISA and 2 tests that detect only patent infection (pleopod and body colour methods) were applied in a 21 mo study. Patent infection was seasonal, appearing predominantly in spring, while subpatent infection diagnosed by ELISA and PCR was highly prevalent in all seasons. Generalised linear modelling supported this assertion, as sampling in September and February significantly increased the probability of finding infected $N$. norvegicus $(\mathrm{p}<0.01)$; infections were predominantly subpatent and patent respectively, at these times. Therefore, Hematodinium seasonality in $N$. norvegicus populations is likely to have been an artefact of insensitive diagnostic tests. Light Hematodinium infections were found using PCR assays when patent infections were at their most prevalent and intense, suggesting that infection develops at different rates in different $N$. norvegicus individuals and that only a portion of the total number of infected $N$. norvegicus die within a single year. These new data were added to a long-term data series for the CSA (1990 to 2008), which showed that after an initial $5 \mathrm{yr}$ epidemic period, prevalence stabilised at 20 to $25 \%$. Comparisons with 'susceptible-infected-recovered/removed' (SIR) models suggest that this high prevalence is maintained through high birth rates of susceptible host $N$. norvegicus.
\end{abstract}

KEY WORDS: Lobster · Parasite · Diagnostic · Disease • Mortality · Long-term dataset • Dinoflagellate $\cdot$ Monitoring $\cdot$ Fisheries

\section{INTRODUCTION}

Commercially valuable Norway lobster Nephrops norvegicus populations can be deleteriously affected by the parasitic dinoflagellate Hematodinium sp. (Alveolata, Syndinea), which can cause significant mortality and loss of fisheries revenue (Field et al. 1992, Appleton \& Vickerman 1998, Briggs \& McAliskey 2002). Hematodinium sp. (hereafter referred to as Hematodinium) has significantly influenced natural mortality in numerous Scottish and Irish $N$. norvegicus populations, in which the parasite occurs annually in up to as much as $40 \%$ of trawl-caught $N$. norvegicus (Field et al. 1992, 1998, Stentiford et al. 2001b, Briggs \& McAliskey 2002). Diagnosing Hematodinium infection in $N$. norvegicus is dependent on the intensity of infection (parasites per infected individual; Bush et al. 1997) in vivo. Specifically, Hematodinium infections in $N$. norvegicus may be without visual manifestation where Hematodinium cells are present in the organs and the haemolymph at low intensities (when $<20 \%$ of the total cells in the 
haemolymph are typically parasite cells) (defined as subpatent) or they may be visible through aggregations of haemocytes and parasite cells in the pleopod blades and vivid changes in cuticle colour (defined as patent) (Field \& Appleton 1995, 1996, Stentiford et al. 2001b,c, Small et al. 2002, Stentiford \& Neil 2011). Using patent infections to estimate the prevalence (the proportion infected from a population subsample; Bush et al. 1997) of $N$. norvegicus and indeed, most hosts, harbouring Hematodinium spp. infections from a population subsample can have numerous implications. Most importantly, patent signs of infection are known to appear late in the infection cycle (Stentiford \& Shields 2005). Therefore these methods may exclude those hosts harbouring subpatent infections. In $N$. norvegicus, this excludes finding infections during the subpatent phase of Hematodinium development that precedes patent infection (Field \& Appleton 1995, 1996, Appleton \& Vickerman 1998, Stentiford et al. 2001c). Therefore, these data may not represent the true infection prevalence at all times.

Using patent signs of infection to diagnose Hematodinium infection in Nephrops norvegicus show Hematodinium infection in $N$. norvegicus to be predominantly a seasonal occurrence in trawl samples, where a peak of infection in late winter and spring is followed by an infection nadir in summer and autumn (Field et al. 1992, Field \& Appleton 1995, Stentiford et al. 2001b, Briggs \& McAliskey 2002). Such seasonal cycles of infection typify Hematodinium infection in most host species (Stentiford \& Shields 2005). Furthermore, patently infected $N$. norvegicus spend significantly more time outside their burrows and show reduced tail-flip response compared with uninfected conspecifics (Stentiford et al. 2000a,b, 2001a). Therefore, $N$. norvegicus harbouring patent infections are more available for capture by trawl gear, and any prevalence measures based on trawl samples of patently infected lobsters may be overestimates.

The number of Nephrops norvegicus harbouring subpatent Hematodinium infections that develop over the summer is unknown. However, PCR and immunoassays indicate that in $N$. norvegicus and numerous other host species, infections exist outside patent infection seasons. For example, using PCR Hamilton et al. (2009) showed that up to $25 \%$ of 7 sympatric decapod species (Cancer pagurus, Carcinus maenas, Liocarcinus depurator, Munida rugosa, Necora puber, Pagurus bernhardus and P. prideaux) from the Clyde Sea area (CSA), Scotland, UK, can be infected with Hematodinium in the summer, whereas peak infection abundance ( $>25 \%$ ) was observed in the winter and spring. A Western-blot immunoassay developed by Stentiford et al. (2001c) showed that subpatent infection in $N$. norvegicus from the CSA can be as prevalent in autumn as patent infections are the following spring. However, this study failed to detect infection in summer. The interpretation drawn from the data presented by Stentiford et al. (2001c) was that infection is not carried over in the host $N$. norvegicus from one season to the next (i.e. infection and patency occur in one season), or that a possible alternate host may be involved to complete the life cycle. Interestingly, a small-scale study by Field \& Appleton (1996), which used the same antibodies in an immuno-fluorescence antibody test (IFAT), found numerous subpatent infections in summer. However, the IFAT was not employed in a large scale study owing to its time-consuming nature. Small et al. (2002) again used the antibodies to develop a high-throughput ELISA that is 4 -fold more sensitive than the Western-blot assay and capable of detecting subpatent infection. Both PCR and ELISA techniques provide scope for elucidating the prevalence of subpatent Hematodinium infections in N. norvegicus, but neither has yet been used on a large scale.

Our aim in this study was to establish the extent to which the lack of detectable Hematodinium infections in Nephrops norvegicus outside seasons of patent infection may simply be an artefact of insensitive diagnostic techniques. We hypothesised that high levels of subpatent Hematodinium infections are detectable in $N$. norvegicus in all seasons. To achieve this, we studied the CSA $N$. norvegicus population in Scotland where, since its discovery in the late 1980s, annual mortality events associated with Hematodinium infection have occurred. A 21 mo prevalence study of Hematodinium was undertaken in the present study using the aforementioned ELISA test (Small et al. 2002) and 2 PCR assays (Gruebl et al. 2002, Small et al. 2006). These assays detect subpatent infections. Additionally we used the colour and pleopod methods. Finally, since the study of Hematodinium sp. in $N$. norvegicus from the CSA was conducted extensively (yet somewhat intermittently) for over $18 \mathrm{yr}$, data from the present study were integrated with those collected previously to form a long-term data series.

\section{MATERIALS AND METHODS}

\section{Capture of Nephrops norvegicus}

Trawl hauls were conducted monthly over $2 \mathrm{yr}$ from December 2006 through September 2008 (ex- 
cluding August 2008) aboard either the RV 'Aplysia' or the RV 'Aora' from the University Marine Biological Station Millport (UMBSM). A transect to the south of Little Cumbrae Island $\left(55^{\circ} 46^{\prime} \mathrm{N}, 4^{\circ} 59^{\prime} \mathrm{W}\right)$ was used primarily (Fig. 1). However, trawls aboard the RV 'Aplysia' were carried out along different transects in September 2006 (from Great Cumbrae through the Isle of Bute; $55^{\circ} 46^{\prime} \mathrm{N}, 4^{\circ} 59^{\prime} \mathrm{W}$ ) and in March 2007 (the Largs-Fairlie channel; 55 46' N, $\left.4^{\circ} 52^{\prime} \mathrm{W}\right)$. From December 2006 up to and including August 2007 (hereafter referred to as Year 1) the body colour and ELISA methods were used for diagnosis. Between September 2007 and September 2008, body colour, pleopod, ELISA and PCR methods were used (hereafter referred to as Year 2).

Trawl depths were between 60 and $110 \mathrm{~m}$. Trawls on RV 'Aora' used a dual-purpose commercial net with $80 \mathrm{~mm}$ diamond-mesh netting, and trawls on RV 'Aplysia' used a research net with a $50 \mathrm{~mm}$ diamond-mesh netting. Trawling duration was approximately $1.5 \mathrm{~h}$ in each case. The towing period generally occurred in the morning, between 09:00 and 12:00 h. After the trawl catch was on deck, 100 Nephrops norvegicus individuals were immediately taken nonselectively and placed in a tank with flow-through seawater. Each individual lobster was immediately assessed for body colour, sex and carapace length (CL), and a sample of haemolymph (that varied according to $N$. norvegicus size) was then withdrawn from the haemal sinus at the base of the fifth pereiopod. The haemolymph sample was either mixed 1:1 with marine anticoagulant (0.1 M glucose, $30 \mathrm{mM}$ trisodium citrate, $26 \mathrm{mM}$ citric acid, $0.45 \mathrm{M} \mathrm{NaCl}, 10 \mathrm{mM}$ EDTA, pH 4.6) or allowed to clot, and subsequently either used im- mediately in ELISA and PCR assays (see below) or frozen at $-20^{\circ} \mathrm{C}$ until use. All haemolymph samples were assayed by ELISA in each month. However, only a proportion of the 100 monthly haemolymph samples were tested by PCR because the quality and quantity of DNA was too low in numerous samples (see below).

Pleopods were viewed with low power microscopy and scored as positive or negative for Hematodinium according to the criteria of Field \& Appleton (1995). The prevalence of subpatent infections was calculated by subtracting the number of patent infections from the total number of infections.

\section{Haemolymph ELISA}

The method used was that of Small et al. (2002) with some modifications. Haemolymph was used at 1:500 with phosphate-buffered saline (PBS) (SigmaAldridge) and coated onto microplates at $50 \mu \mathrm{l}$ per well. The primary anti-Hematodinium antibody was diluted 1:5000 in PBS and the secondary antibody (goat against rabbit immunoglobin $\mathrm{G}$ [IgG] conjugated with horseradish peroxidase [SigmaAldridge]) was diluted 1:10000 in PBS. A tetramethylbenzidine ultra-slow ELISA substrate for horseradish peroxidase (Sigma-Aldridge) was used to develop the colour reaction, for $5 \mathrm{~min}$ at room temperature. Colour intensity was read at a wavelength of $560 \mathrm{~nm}$. Positive controls (haemolymph from Nephrops norvegicus with body colour-positive Hematodinium infections) and negative controls (uninfected $N$. norvegicus haemolymph) were run in duplicate on each plate.

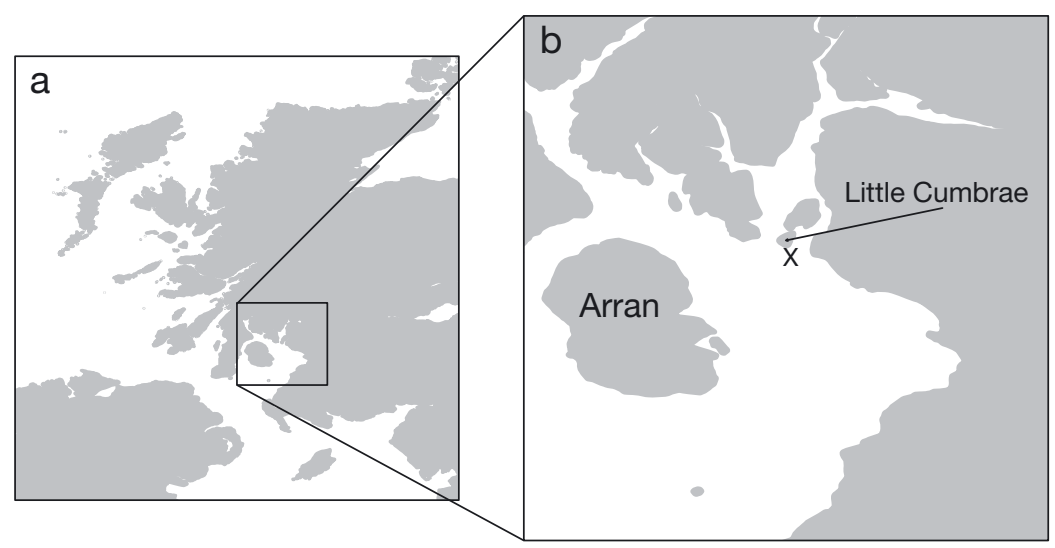

Fig. 1. (a) Western Scotland showing (b) the trawl transect location (X) south of Little Cumbrae Island in the Clyde Sea area used in the present study and also in those studies listed in Table 3

\section{DNA extraction}

Haemolymph/anticoagulant samples or frozen clots were initially placed in $250 \mu$ of extraction buffer (50 mM Tris, 5 mM EDTA, 100 mM NaCL, pH 8), $100 \mu \mathrm{l}$ of $10 \%$ sodium dodecyl sulphate (SDS) solution (10\% SDS in extraction buffer), $10 \mu \mathrm{l}$ of Proteinase $\mathrm{K}$ (New England Biolabs) (10 $\left.\mu \mathrm{g} \mathrm{ml}^{-1}\right)$ and shaken overnight at $56^{\circ} \mathrm{C}$. DNA was collected using both a DNEasy Blood and Tissue Kit (Qiagen) according to manufacturer's protocols, or by the phenol-chloroform extraction method using standard procedures. 
The quality of DNA was observed on $1.5 \%(\mathrm{w} / \mathrm{v})$ agarose gels according to standard procedures, and the quantity was measured using the Nanodrop ${ }^{\mathrm{TM}}$ system (Thermo-Fisher Scientific). Once resuspended, if a haemolymph DNA extract was less than $\sim 10 \mathrm{ng}^{-1}$ and was accompanied by a visual inspection of quality that deemed no DNA was present (on the gel), the sample was not tested by PCR. However, these samples were still tested by ELISA and visual methods.

\section{PCR screening}

Two PCR primer sets were used to screen haemolymph samples collected from trawl surveys. Both primer sets amplified DNA from the rRNA gene complex. Primer Set 1 (developed by Gruebl et al. 2002) employed the Hemat-F-1487 (5'-cct ggc tcg ata gag ttg-3') and Hemat-R-1654 (3'-ggc tgc cgt ccg aat tat tca c-5') primers resulting in a $187 \mathrm{bp}$ amplicon. This assay has a reported sensitivity of 1 parasite cell per 300000 host haemocytes. PCR was performed using $50 \mu$ total reaction volumes; the GoTaq ${ }^{\circledR}$ (Promega) system was used for the PCR mastermix. The mastermix consisted of $10 \mu$ of $5 \times$ buffer mix (New England Biolabs), $1.25 \mu \mathrm{l}$ of the forward and reverse primers (10 $\mu \mathrm{m}$ each), $0.625 \mu \mathrm{l}$ of dNTPs $(10 \mathrm{mM}$ each nucleotide) (New England Biolabs), $0.25 \mu \mathrm{l}$ Taq polymerase (New England Biolabs), $10 \mathrm{ng}$ of the sample DNA and double-distilled water $\left(\mathrm{ddH}_{2} \mathrm{O}\right)$ to $50 \mu \mathrm{l}$. PCR thermal cycling was performed as in Gruebl et al. (2002). Samples were stored at $4^{\circ} \mathrm{C}$ (less than $24 \mathrm{~h}$ ) or $-20^{\circ} \mathrm{C}$ (long term) until gel electrophoresis was conducted.

Primer Set 2 (developed by Small et al. 2006) was used to screen for the Hematodinium genotype infecting Nephrops norvegicus and other UK crustaceans (Small et al. 2007, Hamilton et al. 2009). The reported sensitivity of the assay was approximately 0.6 parasites per reaction volume $(1 \mathrm{ng}$ genomic DNA). The primer pair 18S F2 (from the 3 ' end of the $18 \mathrm{~S}$ gene; $5^{\prime}$-cag ttt ctg gaa gtg gca gct g- $3^{\prime}$ ) and ITS R1 (3'-gaa ggg aag ggg aga aga agc-5') resulted in an approximately $380 \mathrm{bp}$ product. The PCR mastermix consisted of $10 \mu \mathrm{l}$ of $5 \times$ buffer mix (New England Biolabs), $1.25 \mu \mathrm{l}$ of the forward and reverse primers (10 $\mu \mathrm{m}$ each), $0.625 \mu \mathrm{l}$ dNTPs $(10 \mathrm{mM}$ each nucleotide) (New England Biolabs), $0.25 \mu \mathrm{l}$ Taq polymerase (New England Biolabs), $10 \mathrm{ng}$ of the sample DNA and $\mathrm{ddH}_{2} \mathrm{O}$ to $50 \mu \mathrm{l}$. PCR thermal cycling was performed as in Small et al. (2006) and samples were stored as above.
A $3 \mu$ sample of each PCR reaction was checked for amplification products by $1.5 \%(\mathrm{w} / \mathrm{v})$ agarose gel electrophoresis and ethidium bromide staining. Images were captured using a BioRad ${ }^{\mathrm{TM}}$ gel documentation system (Bio-Rad). Positive and negative Hematodinium controls were run alongside all screening PCR reactions. Infected material for positive controls came from heavily infected Nephrops norvegicus haemolymph samples and sterile $\mathrm{ddH}_{2} \mathrm{O}$ was used as negative control to identify contamination. Haemolymph samples from September and October 2007 and January to August 2008 were screened by both primer sets, whereas those from November and December 2007 were screened by Primer Set 1 and the positives from these months were then screened by Primer Set 2 .

\section{Construction of long-term Hematodinium data series}

Previous data on Hematodinium prevalence available for the South Little Cumbrae (SLC) transect over the period 1990 to 2005 were collated from published papers and unpublished reports, in which information on methods of collection and prevalence were documented. Where Hematodinium prevalence was estimated by trawling more than once within a month, maximal prevalence values were used. These were added to the data generated in the current study.

\section{Statistical analysis}

ELISA and PCR data (see above) from Nephrops norvegicus caught in Year 2 (11 mo, exclusive of August 2008) were used to analyse the effect of size, sex and month of capture on the probability of finding infection using generalised linear modelling. Infection was the binomial response variable with size (continuous), sex (categorical) and month (categorical) as covariates. Initially, interactions between sex and size and between month and size were included in the model along with the covariates listed above. These interactions were included for 2 reasons: (1) previous reports of sex and size of infected $N$. norvegicus in the CSA suggested that small $N$. norvegicus, particularly small females, were more predisposed to infection than larger individuals, and (2) female prevalence was much higher in periods where sex ratios are skewed to males. The nonsignificant predictors of infection were systematically 
removed until only significant predictors remained. All statistical analyses were performed using the SPSS v. 15.0 statistics package. A significance level of $p<0.05$ was used throughout.

\section{RESULTS}

\section{Nephrops norvegicus population trends over the sampling period}

The sex ratios of Nephrops norvegicus caught by the trawls over the sampling period November 2006 to September 2008 showed that males dominated the trawl catches for 9 mo of each of the $2 \mathrm{yr}$, but during the months of May, June and July sex ratios were generally even, with slight female predominance. This pattern has previously been shown to represent the emergence of females from their burrows during the spring, prior to moulting and mating (see Stentiford et al. 2001b, Milligan et al. 2009). After the periods of maximum female emergence (May, June and July), catches were dominated by male lobsters.

\section{Hematodinium infection}

Body colour-positive Nephrops norvegicus were present in the trawls between February and June of 2007 (4 mo) and between January and July of 2008

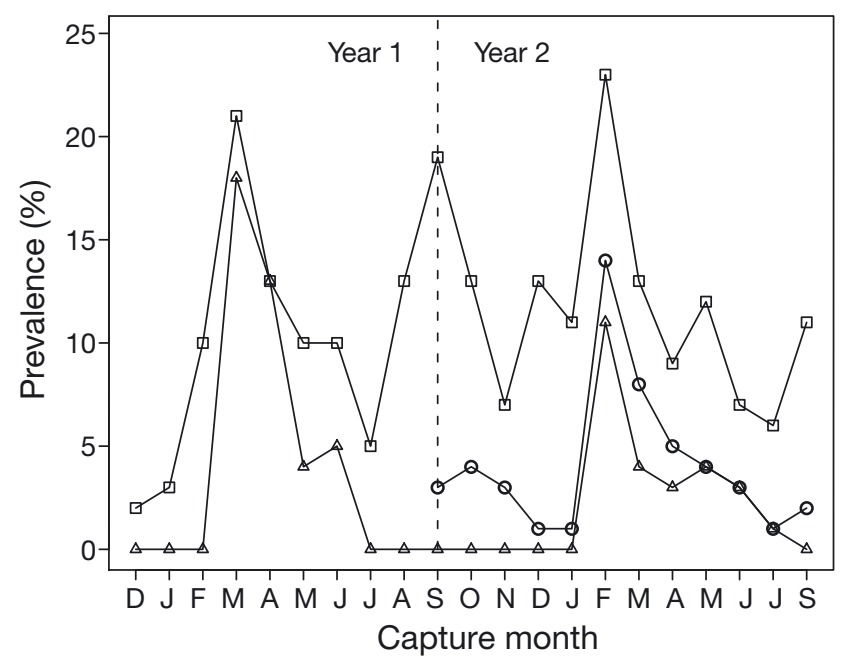

Fig. 2. Hematodinium infection prevalence estimates for Nephrops norvegicus from monthly trawl subsamples from the Little Cumbrae site between December 2006 and September 2008 (exclusive of August 2008). (ㅁ) ELISA, (O) pleopod method and $(\Delta)$ body colour method data are shown. Year 1 and Year 2 are separated by a dotted line, and Year 2 includes September 2007
(6 mo) (Fig. 2). Prevalence of body colour-positive $N$. norvegicus peaked in the spring at $18 \%$ (March) and $11 \%$ (February) in the $2 \mathrm{yr}$, respectively.

Pleopod-positive Nephrops norvegicus were present in every month in which the pleopod method was used (Fig. 2). Prevalence by the pleopod method showed peak abundance in February 2008 (14\%), which closely matched the prevalence of Hematodinium by body colour. However, numerous pleopodpositive $N$. norvegicus were present before the body colour method had detected any infection between September and January 2007. In February 2008, when body colour-positive $N$. norvegicus were at maximum prevalence, 3 infected $N$. norvegicus were positive by the pleopod method but not by body colour.

All Nephrops norvegicus that were positive by the body colour and pleopod methods were positive by ELISA. Furthermore, the ELISA detected subpatent infection in every month. Infection prevalence by ELISA peaked in late winter and summer of Year 1 and spring in Year 2. The ELISA test also showed reduction in prevalence after the disappearance of $N$. norvegicus that were positive by body colour (in early summer). However, unlike the body colour and pleopod methods, which showed that there was an infection nadir in summer, prevalence by ELISA peaked again in late summer and early autumn.

The emergence of patent infection and the levels of concurrent subpatent infections as diagnosed by ELISA characterised the $2 \mathrm{yr}$ of the study differently (Fig. 2). In the months leading up to maximal body colour-prevalence in Year 1, there were around half the number of subpatent infections seen in the same period in Year 2 ( $\mathrm{n}=15$ and 31, respectively). In the subsequent months, maximal body colour prevalence was seen in March (18\%) when 3 Nephrops norvegicus that were ELISA-positive had yet to develop the body colour associated with advanced infection. This is considerably lower than the following year when there were still 3 pleopod-positive and 11 ELISA-positive $N$. norvegicus that had yet to develop change in body colour. Also, in Year 2, N. norvegicus exhibiting body colour change persisted for longer although the maximal value for body colour prevalence was lower than in Year 1.

Between 54 and $90 \%$ of Nephrops norvegicus haemolymph samples were examined with PCR assays each month. However, PCR detected infections than were not detected by the ELISA (i.e. PCR positive but ELISA negative), which, when incorporated, increased prevalence values in all but 2 mo (Fig. 3). The ELISA misdiagnosed up to $40 \%$ of the 


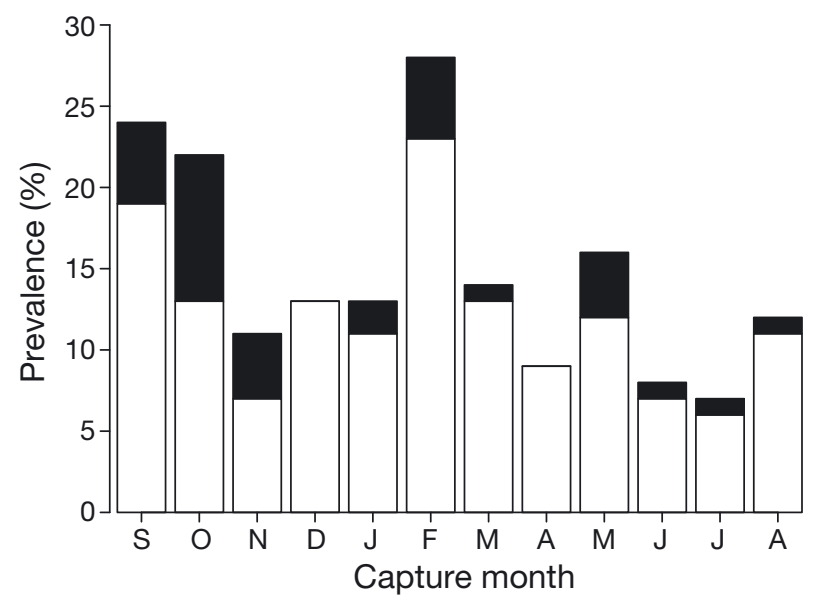

Fig. 3. Hematodinium infection prevalence estimates for Nephrops norvegicus from the Little Cumbrae site for Year 2 of the study (September 2007 to September 2008, exclusive of August 2008). Prevalence (\%) data determined by ELISA (open bars) and PCR (solid bars) are presented. ELISA data includes all $N$. norvegicus that tested positive by the body colour and pleopod methods. PCR positives are in addition to those $N$. norvegicus that tested positive by ELISA total infected $N$. norvegicus as negative for the parasite. In a single month as much as an additional $9 \%$ of trawled $N$. norvegicus were Hematodinium infected according to PCR alone (see Table 1, Fig. 3).

Month significantly affected the probability of finding infected Nephrops norvegicus (Table 1). Specifically, September 2007 and February 2008 showed significantly more probability of finding infection compared with the other months of Year 2 (Table 2). However, the peak of infection in September 2007 was due to subpatent infections whilst in February 2008 there were twice as many patent infections (Fig. 4). Subpatent infections were present in all seasons (Fig. 4). The level of subpatent infection detected was higher in Year 2 because of the more sensitive PCR assays used.

Sex had no significant effect on the probability of finding Hematodinium infection in Nephrops norvegicus ( $\mathrm{p}>0.05)$. However, decreasing body size significantly affected the probability of infection (Fig. 5, Table 1).
Table 1. Relationships between the different diagnostic assays and visual tests for Hematodinium in Nephrops norvegicus. The columns indicate sampling months (Month) from December 2006 through September 2008 (exclusive of August 2008); the prevalence (\%) of $N$. norvegicus with Hematodinium infections in trawl subsamples as diagnosed by (A) ELISA (ELISA prev), (C) pleopod (Pleopod prev) and (D) body colour (Body colour prev) methods; (B) the number of $N$. norvegicus that had subpatent infections detectable only by PCR (No. PCR+ \& ELISA-). The prevalence of subpatent infections (Subpatent prev) and the total prevalence of infected $N$. norvegicus were derived as indicated by the letters heading those columns

\begin{tabular}{|lcccccc|}
\hline Month & $\begin{array}{c}\text { A } \\
\text { ELISA } \\
\text { prev (\%) }\end{array}$ & $\begin{array}{c}\text { B } \\
\text { No. PCR+ }\end{array}$ ELISA- & $\begin{array}{c}\text { C } \\
\text { Pleopod } \\
\text { prev (\%) }\end{array}$ & $\begin{array}{c}\text { Dody colour } \\
\text { prev }(\%)\end{array}$ & $\begin{array}{c}\text { A+B-C } \\
\text { Subpatent } \\
\text { prev }(\%)\end{array}$ & $\begin{array}{c}\text { A+B } \\
\text { Total prev } \\
(\%)\end{array}$ \\
\hline Dec 06 & 2 & - & - & 0 & 2 & 2 \\
Jan 07 & 3 & - & - & 0 & 3 & 3 \\
Feb 07 & 10 & - & - & 0 & 10 & 10 \\
Mar 07 & 21 & - & - & 18 & 3 & 21 \\
Apr 07 & 13 & - & - & 13 & 0 & 13 \\
May 07 & 10 & - & - & 4 & 6 & 10 \\
Jun 07 & 10 & - & - & 5 & 5 & 10 \\
Jul 07 & 5 & - & - & 0 & 5 & 5 \\
Aug 07 & 13 & - & - & 0 & 13 & 13 \\
Sep 07 & 19 & 5 & 3 & 0 & 21 & 24 \\
Oct 07 & 13 & 9 & 4 & 0 & 18 & 22 \\
Nov 07 & 7 & 4 & 3 & 0 & 8 & 11 \\
Dec 07 & 13 & 0 & 1 & 0 & 12 & 13 \\
Jan 08 & 11 & 2 & 1 & 0 & 12 & 13 \\
Feb 08 & 23 & 5 & 14 & 11 & 14 & 28 \\
Mar 08 & 13 & 1 & 8 & 4 & 6 & 14 \\
Apr 08 & 9 & 0 & 5 & 3 & 4 & 9 \\
May 08 & 12 & 4 & 4 & 4 & 12 & 16 \\
Jun 08 & 7 & 1 & 3 & 3 & 5 & 8 \\
Jul 08 & 6 & 1 & 1 & 1 & 6 & 7 \\
Sep 08 & 11 & 1 & 2 & 0 & 10 & 12 \\
\hline
\end{tabular}

\section{Historical data set}

The references from which the long-term data series was constructed are listed in Table 3. The data describe an initial epidemic prevalence in 1990 (the highest prevalence), which oscillated on a declining trajectory until 1995, after which levels decreased to relatively low values for 2 yr (1996 to 1998) (Fig. 6a). However, by 1998 a period of stability in Hematodinium prevalence was established. This can be seen by observing the apparently stable annual prevalence peaks (Fig. 6b). For the last $10 \mathrm{yr}$ (1998 to 2008), Hematodinium prevalence in the CSA has remained stable, showing consistent annual prevalence peaks of 20 to $25 \%$.

\section{DISCUSSION}

In the present study, Hematodinium infections in Nephrops norvegicus from the CSA were found not to be seasonal occurrences. This classification can only be ascribed to the appearance of patent infections. As 
Table 2. Estimates for the logistic regression testing the effects of size and month on the probability of Hematodinium infection in Nephrops norvegicus. September 2008 is not shown, as this month was the baseline. Sampling in September 2007 and February 2008 and sampling smaller N. norvegicus significantly affected the probability of being infected

\begin{tabular}{|lrrrrrr|}
\hline Variable & Estimate & SE & $\begin{array}{c}\text { Wald } \\
\text { statistic }\end{array}$ & df & $p$ & $\begin{array}{c}\text { Odds } \\
\text { ratio }\end{array}$ \\
\hline Month & & & 35.96 & 11 & $<0.01$ & \\
Sep 07 & 0.93 & 0.39 & 5.50 & 1 & $<0.05$ & 2.53 \\
Oct 07 & 0.63 & 0.40 & 2.42 & 1 & $>0.05$ & 1.88 \\
Nov 07 & 0.11 & 0.46 & 0.05 & 1 & $>0.05$ & 1.11 \\
Dec 07 & 0.22 & 0.44 & 0.25 & 1 & $>0.05$ & 1.24 \\
Jan 08 & 0.40 & 0.44 & 0.85 & 1 & $>0.05$ & 1.50 \\
Feb 08 & 1.50 & 0.40 & 14.20 & 1 & $<0.01$ & 4.52 \\
Mar 08 & 0.60 & 0.43 & 1.91 & 1 & $>0.05$ & 1.83 \\
Apr 08 & -0.09 & 0.49 & 0.03 & 1 & $>0.05$ & 0.91 \\
May 08 & 0.52 & 0.42 & 1.54 & 1 & $>0.05$ & 1.69 \\
Jun 08 & 0.11 & 0.46 & 0.06 & 1 & $>0.05$ & 1.12 \\
Jul 08 & -0.34 & 0.50 & 0.45 & 1 & $>0.05$ & 0.70 \\
Size & -0.08 & 0.01 & 21.02 & 1 & $<0.01$ & 0.91 \\
\hline
\end{tabular}

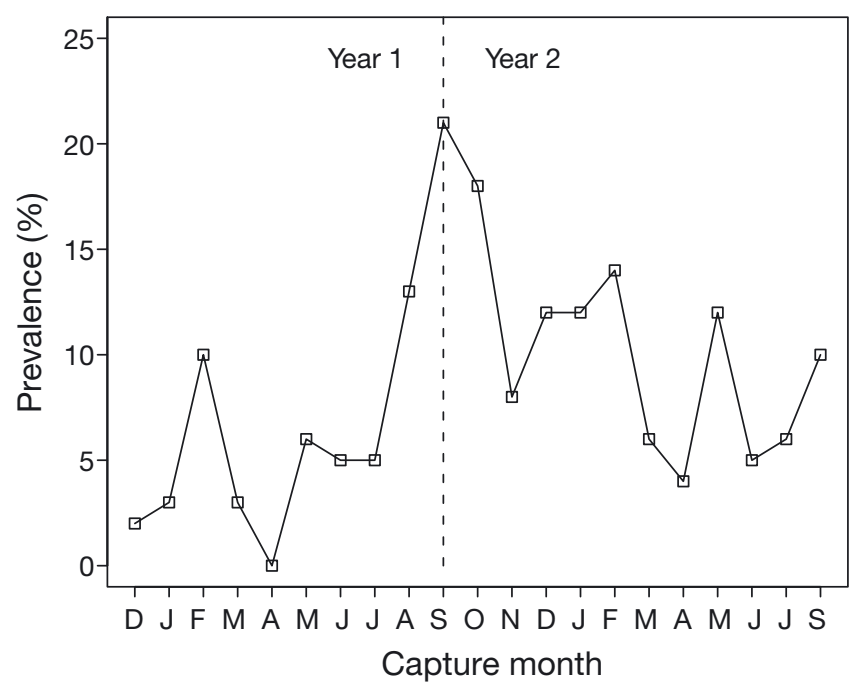

Fig. 4. Prevalence of subpatent Hematodinium infections in Nephrops norvegicus from the Little Cumbrae site between December 2006 and September 2008 (exclusive of August 2008). Year 1 and Year 2 are separated by a dotted line, and Year 2 includes September 2007

expected, the body colour and pleopod methods showed infection to be common in winter and spring, which corroborates previous data sets collected using these methods in N. norvegicus (Field et al. 1998, Stentiford et al. 2001b, Briggs \& McAliskey 2002). However, these methods masked a fluctuating and often high presence of subpatent ELISA- and PCRpositive $N$. norvegicus in all seasons. Our hypothesis

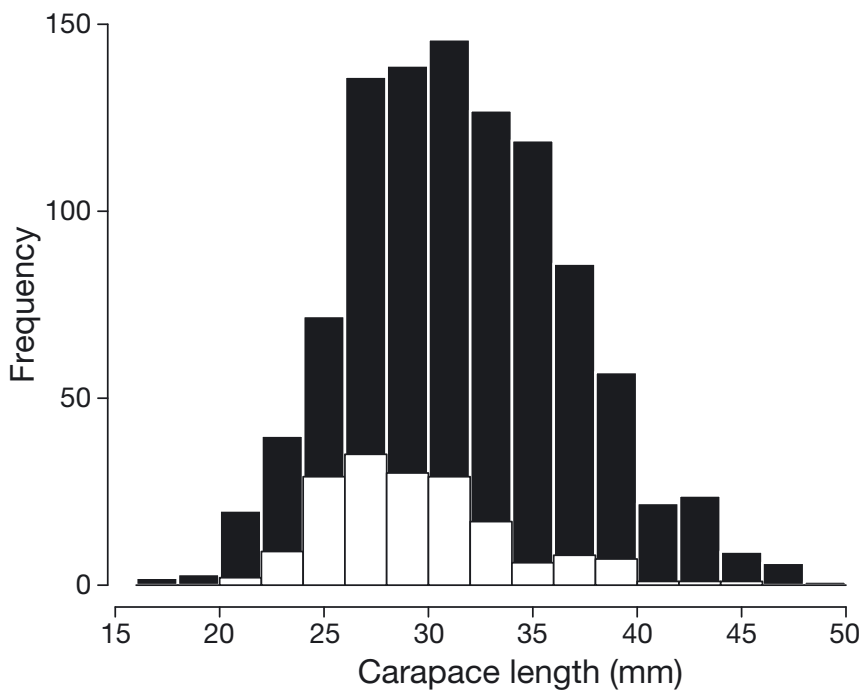

Fig. 5. Carapace length-frequency distribution of uninfected Nephrops norvegicus (solid bars) and Hematodiniuminfected N. norvegicus (open bars) for the South Little Cumbrae site over Year 2 of the study (ELISA and PCR data combined)

that a high prevalence of subpatent Hematodinium infection is detectable in $N$. norvegicus in all seasons is supported by these data. Although subpatent prevalence could be as low as $5 \%$ it could also be as high as $21 \%$ over the period separating patent infection seasons. Such a high prevalence of subpatent infections has not been observed previously during this period in N. norvegicus from the CSA. Previously, Hematodinium infection in summer was a prominent feature in both years with September 2007 showing a statistically significant peak. In addition, a small-scale tank study undertaken in conjunction with the present study showed that $N$. norvegicus with subpatent infections (as screened by ELISA) in July subsequently developed parasite aggregations in the pleopods, moulted in January the following year, developed (immediately) the body colour change and died in the following February (Beevers 2010). This agrees with previous estimates of Hematodinium pathogenesis in $N$. norvegicus and also in the cold-water tanner crab Chionoecetes bairdi and snow crab C. opilio hosts (Meyers et al. 1990, Appleton 1996, Shields et al. 2005). More experiments are required to substantiate this point, however, as the number of $N$. norvegicus that survived in our small scale study was low. We cannot exclude the possibility that infection and death may still occur in the same year.

For Nephrops norvegicus, the ELISA and PCR assays herein have extended the period over which subpatent Hematodinium infections are detectable. 
Table 3. Source material for the long-term Hematodinium data series from the Clyde Sea Area, expressed as number of Nephrops norvegicus sampled per month. These are expressed either as the actual number of N. norvegicus sampled (denoted by $n)$ or as calculated mean values $(\bar{x} \pm \mathrm{SD})$ of the number sampled monthly

\begin{tabular}{|lllcl|}
\hline Year & Reference & Diagnostic test & $\begin{array}{c}\text { Net mesh size } \\
(\mathrm{mm})\end{array}$ & $\begin{array}{l}\text { No. sampled } \\
\text { per month }\end{array}$ \\
\hline $1990-1991$ & Field et al. (1992, unpubl.) & Body colour, pleopod & 22 & $\bar{x}=44.28( \pm 38)$ \\
$1992-1998$ & Field et al. (1998) & Pleopod & 22 & $\bar{x}=147.15( \pm 81.66)$ \\
$1998-2000$ & Stentiford et al. (2001b) & Pleopod & 70 & $\bar{x}=221.28( \pm 62.60)$ \\
2000 & Small et al. (2002) & ELISA & 70 & $\mathrm{n}=30$ \\
$2002-2003$ & Small (2004) & ELISA & 70 & $\mathrm{n}=100$ \\
$2004-2005$ & Authors' unpubl. data & ELISA & 80 & $\mathrm{n}=100$ \\
$2007-2009$ & Beevers (2010) & ELISA, PCR & 80 & $\mathrm{n}=100$ \\
\end{tabular}

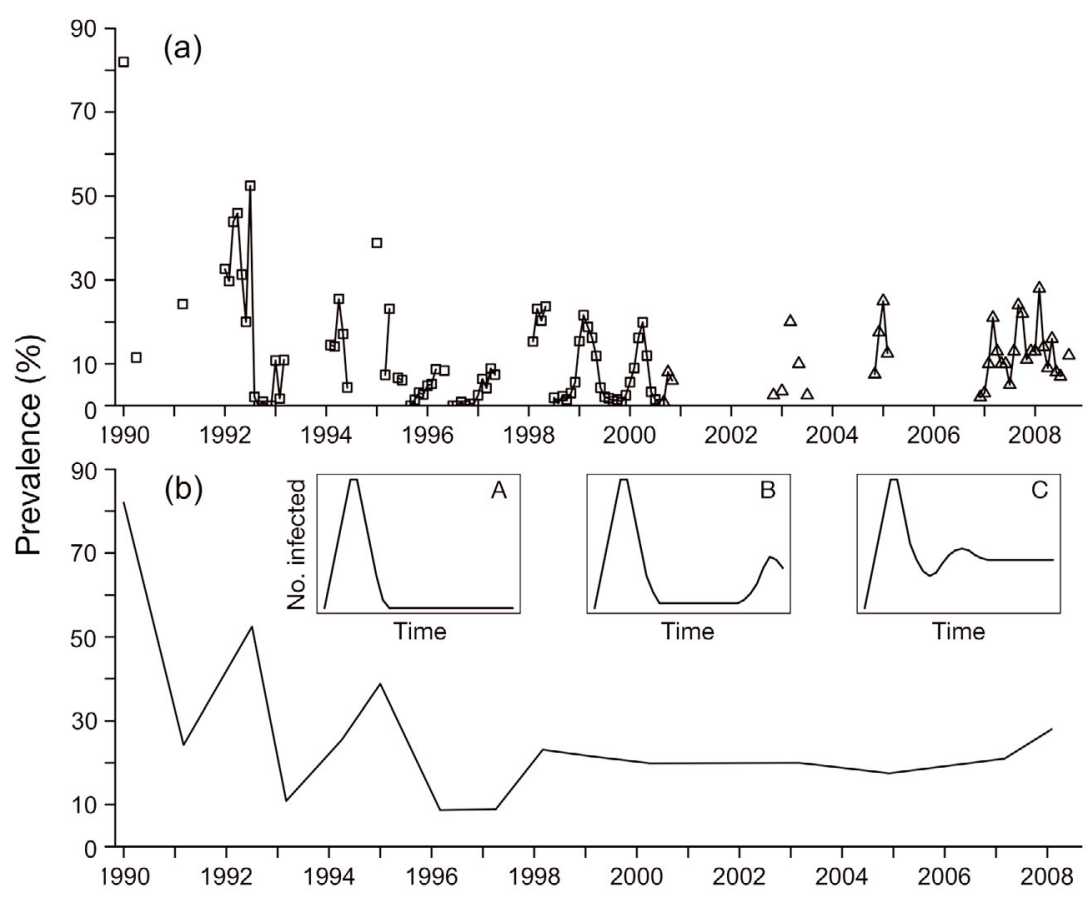

Fig. 6. (a) Plot of the long-term data set collected by the University of Glasgow showing Hematodinium prevalence in Nephrops norvegicus on the South Little Cumbrae transect of the Clyde Sea area from 1990 to 2008 according to: patent infection methods ( $\square$ : pleopods, body colour) and methods capable of detecting subpatent infection ( $\triangle$ : ELISA, PCR). Monthly samples that are consecutive month by month are linked by lines. Points where no data exist are blank without symbols. (b) Plot of the highest Hematodinium prevalence values from each year of the long-term data set. Inset schematics are adapted from Swinton et al. (2002) and are theoretical examples presented for comparison: Schematic (A) describes an epidemic in which host birth rate cannot replace disease-related mortality and the host population and pathogen dies out; Schematic (B) describes an epidemic followed by chance recruitment of susceptible hosts; Schematic (C) describes how a pathogen is maintained endemically because host birth rate is high

Using a Western-blot immunoassay Stentiford et al. (2001c) found that subpatently infected $N$. norvegicus are either absent or undetectable in the CSA in summer. Our data support the latter. The Western-blot immunoassay used by Stentiford et al. (2001c) is 4- fold less sensitive than the ELISA test used in the present study (Small et al. 2002). Therefore, we could detect less advanced infections. In addition, the PCR assays found even more infections in all seasons that were undetected by ELISA. Using PCR tests comparable in sensitivity to those used in the present study, Hamilton et al. (2010) detected summer Hematodinium prevalences as high as $25 \%$ in numerous sympatric decapod species from the CSA (exclusive of $N$. norvegicus). In that study, peaks of prevalence were in winter and spring. In the present study and also in Hamilton et al. (2010), infection intensity was not recorded in individual hosts. However, we did use 4 diagnostic tests with a wide range of sensitivities on each $N$. norvegicus individual. This allowed us to show that at certain time points, infection intensity may vary considerably and that this may have implications for quantifying levels of Hematodinium-associated mortality in this species.

Only a proportion of the total number of Nephrops norvegicus hosts that are infected during the patent infection season may succumb to the parasite. In infected hosts, mortality associated with Hematodinium is concurrent with the highest infection intensities (Stentiford \& Shields 2005). This relationship can predict when mortality will occur (Messick \& Shields 2000, Ni Chualain \& Robinson 2011). The period in which mortality associated with Hematodinium occurs in $N$. norvegicus populations is when body colour-positive lobsters are present in 
trawls (Field et al. 1992). This period was from February to July 2008 in Year 2 of the present study. In February 2008 for example, body colour-positive $N$. norvegicus were at their most prevalent (11\%) and it was likely that these animals contained Hematodinium cells that would soon sporulate and exit the host (Field et al. 1992, Appleton 1996, Beevers 2010). However, there were also $5 \mathrm{~N}$. norvegicus that tested positive only by PCR in that month. Such infections could be as low as one parasite cell per 300000 host haemocytes (Gruebl et al. 2002). If subpatent infections detected by ELISA can take up to 10 mo to reach patency, low level PCR-positive infections may take even longer (Beevers 2010). This challenges previous reports of Hematodinium in N. norvegicus that suggest all infections culminate in a single bout of high infection in late winter and spring (Field et al. 1998, Stentiford et al. 2001b, Briggs \& McAliskey 2002). If it is assumed that infection always leads to host death, then finding PCR-positive $N$. norvegicus in February 2008 suggests that infection develops at distinctly different rates in different $N$. norvegicus individuals throughout the year, and that either only a fraction of the total number of infected $N$. norvegicus found at times of peak prevalence will succumb to infections in that year or that PCR detected very light infections that may be cleared by the $N$. norvegicus host.

Finding previously undetected infections of $\mathrm{He}$ matodinium in Nephrops norvegicus using ELISA and PCR methodologies may have implications for sex specificity, duration of infection and underlying prevalence. Crustacean parasites with a predilection for certain hosts of a particular sex can exacerbate prevalence, and it was previously reported that small female $N$. norvegicus were more susceptible to Hematodinium (Kuris \& Lafferty 1992, Field et al. 1998, Stentiford et al. 2001b). However, sex did not affect the probability of Hematodinium infection in the present study. We now suggest that males and females are more equal in terms of susceptibility. It is also possible that subpatent infections can persist for long periods in $N$. norvegicus without manifesting as patent infection. Using a nested PCR approach in a Danish $N$. norvegicus population with no history of patent Hematodinium infection, Eigemann et al. (2010) found prevalence of subpatent Hematodinium infection to be around $65 \%$. Those authors concluded that if the Hematodinium DNA amplified by the PCR was from viable cells, infections may not always be fatal. The same may be happening in $N$. norvegicus from the CSA and this may confound attempts to forecast parasite-induced mortality. Finally, patently infected $N$. norvegicus are more available for capture by trawl gear during seasons of patent infection. Therefore, prevalence estimates based on trawl samples of patently infected lobsters may be overestimates (Stentiford et al. 2000a,b, 2001a). However, in summer, when the parasite burden is very low, its effect on host behaviour and physiology will be minimal, thus resulting in no difference in their catchability compared with uninfected lobsters. The prevalence measures made from trawl catches during subpatent seasons may therefore be more accurate representations of underlying prevalence of Hematodinium infection.

Prevalence of Hematodinium infection in Nephrops norvegicus at present is considerably lower than when monitoring in the CSA began. Prevalences reported beginning in 1990 are indicative of an initial 3 yr epizootic (1990 to 1992) in the CSA $N$. norvegicus population. More recently, the observed homogeneity in annual Hematodinium infection levels probably represents a (post epizootic) enzootic level. A factor to consider may be that that the 22 mm mesh size used from 1990 and 1998 may have yielded catches with different compositions compared with the $80 \mathrm{~mm}$ net used thereafter. However, even by selecting for the $N$. norvegicus most likely to be infected (20 to $30 \mathrm{~mm} \mathrm{CL}$, Beevers 2010), it is not currently possible to recreate such prevalence values from a single research trawl. The size and density of $N$. norvegicus on the SLC transect have remained stable over the last $8 \mathrm{yr}$. Furthermore, the size and prevalence of infected $N$. norvegicus have also remained stable. This is interesting considering the high prevalence of Hematodinium in this population and consistently high fishing effort (Stentiford et al. 2001b, Milligan et al. 2009). Comparing these long-term data with 'susceptible-infected-recovered/removed' (SIR) epidemiological models may be useful. SIR models have been used to elucidate similar epidemicendemic transitions (Swinton et al. 2002) and intriguing similarities exist between the long-term prevalence of Hematodinium in the CSA and theoretical populations that support continued high pathogen prevalence through high birth rates of susceptible hosts (see Fig. 6). These data are at the level of detail necessary to observe long-term patterns of Hematodinium prevalence in the CSA. Whilst beyond the scope of this work, these data could form the basis of a substantial mathematical modelling exercise that may elucidate how $N$. norvegicus hosts sustain Hematodinium at current levels. 
Acknowledgements. This work was supported by a CASE studentship to N.D.B. from the UK Biotechnology and Biological Sciences Research Council in association with Young's Seafood Ltd. The authors thank skippers M. Parker and D. Fraser and the crew of RV 'Aora' and skippers H. McCrindle and C. McLachlan from the RV 'Aplysia' for their assistance in the collection of lobster specimens. We also thank Drs. S. Townsend and A. Albalat for assistance in the preparation of the manuscript.

\section{LITERATURE CITED}

Appleton PL (1996) Investigations on the cytology and life cycle of the parasitic dinoflagellate parasite Hematodinium sp. associated with mortality of Nephrops norvegicus. PhD dissertation, University of Glasgow

> Appleton PL, Vickerman K (1998) In vitro cultivation and developmental cycle in culture of a parasitic dinoflagellate (Hematodinium sp.) associated with mortality of the Norway lobster (Nephrops norvegicus) in British waters. Parasitology 116:115-130

Beevers N (2010) Prevalence and life cycle studies on the parasitic dinoflagellate Hematodinium sp. from Nephrops norvegicus (L.). PhD dissertation, University of Glasgow

Briggs RP, McAliskey M (2002) The prevalence of Hematodinium in Nephrops norvegicus from the western Irish Sea. J Mar Biol Assoc UK 82:427-433

> Bush AO, Lafferty KD, Lotz JM, Shostak AW (1997) Parasitology meets ecology on its own terms: Margolis et al. revisited. J Parasitol 83:575-583.

Eigemann F, Burmeister A, Skovgaard A (2010) Hematodinium sp. (Alveolata, Syndinea) detected in marine decapod crustaceans from waters of Denmark and Greenland. Dis Aquat Org 92:59-68

Field RH, Appleton PL (1995) A Hematodinium-like dinoflagellate infection of the Norway lobster Nephrops norvegicus: observations on pathology and progression of infection. Dis Aquat Org 22:115-128

> Field RH, Appleton PL (1996) An indirect fluorescent antibody technique for the diagnosis of Hematodinium sp. infection of the Norway lobster Nephrops norvegicus. Dis Aquat Org 24:199-204

Field RH, Chapman CJ, Taylor AC, Neil DM, Vickerman K (1992) Infection of the Norway lobster Nephrops norvegicus by a Hematodinium-like species of dinoflagellate on the west coast of Scotland. Dis Aquat Org 13:1-15

Field RH, Hills JM, Atkinson RJA, Magill S, Shanks AM (1998) Distribution and seasonal prevalence of Hematodinium sp. infection of the Norway lobster (Nephrops norvegicus) around the west coast of Scotland. ICES J Mar Sci 55:846-858

Gruebl T, Frischer ME, Sheppard M, Neumann M, Maurer AN, Lee RF (2002) Development of an 18S rRNA genetargeted PCR-based diagnostic for the blue crab parasite Hematodinium sp. Dis Aquat Org 49:61-70

> Hamilton K, Shaw P, Morritt D (2009) Prevalence and seasonality of Hematodinium (Alveolata: Syndinea) in a Scottish crustacean community. ICES J Mar Sci 66:1837-1845

> Hamilton KM, Morritt D, Shaw PW (2010) Genetic diversity of the crustacean parasite Hematodinium (Alveolata, Syndinea). Eur J Protistol 46:17-28

Kuris AM, Lafferty KD (1992) Modelling crustacean fisheries: effects of parasites on management strategies. Can J Fish Aquat Sci 49:327-336

Messick GA, Shields JD (2000) Epizootiology of the parasitic dinoflagellate Hematodinium sp. in the American blue crab Callinectes sapidus. Dis Aquat Org 43:139-152

- Meyers TR, Botelho C, Koeneman TM, Short S, Imamura K (1990) Distribution of bitter crab dinoflagellate syndrome in southeast Alaskan tanner crabs Chionoecetes bairdi. Dis Aquat Org 9:37-43

Milligan RJ, Albalat A, Atkinson RJA, Neil DM (2009) The effects of trawling on the physical condition of the Norway lobster Nephrops norvegicus in relation to seasonal cycles in the Clyde Sea area. ICES J Mar Sci 66:488-494

Ni Chualain CN, Robinson M (2011) Comparison of assessment methods used to diagnose Hematodinium sp. infections in Cancer pagurus. ICES J Mar Sci 68:454-462

Shields JD, Taylor DM, Sutton SG, Collins PW, Ings DW, Pardy AL (2005) Aspects of the epidemiology of bitter crab disease (Hematodinium sp.) in snow crabs, Chionoecetes opilio from Conception Bay, Newfoundland. Res Doc 2004/077, Canadian Science Advisory Secretariat, Ottawa

Small H (2004) Infections of the Norway lobster, Nephrops norvegicus (L.) by dinoflagellate and ciliate parasites. $\mathrm{PhD}$ dissertation, University of Glasgow

> Small HJ, Wilson S, Neil DM, Hagan P, Coombs GH (2002) Detection of the parasitic dinoflagellate Hematodinium in the Norway lobster Nephrops norvegicus by ELISA. Dis Aquat Org 52:175-177

- Small HJ, Neil DM, Taylor AC, Atkinson RJA, Coombs GH (2006) Molecular detection of Hematodinium spp. in Norway lobster Nephrops norvegicus and other crustaceans. Dis Aquat Org 69:185-195

Small HJ, Shields JD, Moss JA, Reece KS (2007) Conservation in the first internal transcribed spacer region (ITS1) in Hematodinium species infecting crustacean hosts found in the UK and Newfoundland. Dis Aquat Org 75:251-258

Stentiford GD, Neil DM (2011) Diseases of Nephrops and Metanephrops: a review. J Invertebr Pathol 106:92-109

Stentiford GD, Shields JD (2005) A review of the parasitic dinoflagellates Hematodinium species and Hematodinium-like infections in marine crustaceans. Dis Aquat Org 66:47-70

Stentiford GD, Neil DM, Atkinson RJA, Bailey N (2000a) An analysis of swimming performance in the Norway lobster, Nephrops norvegicus L., infected by a parasitic dinoflagellate of the genus Hematodinium. J Exp Mar Biol Ecol 247:169-181

Stentiford GD, Neil DM, Coombs GH (2000b) Alterations in the biochemistry and ultrastructure of the deep abdominal flexor muscle of the Norway lobster Nephrops norvegicus during infection by a parasitic dinoflagellate of the genus Hematodinium. Dis Aquat Org 42:133-141

Stentiford G, Neil DM, Atkinson RJA (2001a) Alteration of burrow-related behaviour of the Norway lobster, Nephrops norvegicus, during infection by the parasitic dinoflagellate Hematodinium. Mar Freshw Behav Physiol 34:139-156

> Stentiford GD, Neil DM, Atkinson RJA (2001b) The relationship of Hematodinium infection prevalence in a Scottish Nephrops norvegicus population to season, moulting and sex. ICES J Mar Sci 58:814-823

> Stentiford GD, Neil DM, Coombs GH (2001c) Development and application of an immunoassay diagnostic technique for studying Hematodinium infections in Nephrops norvegicus populations. Dis Aquat Org 46:223-229

Swinton J, Woolhouse MEJ, Begon ME, Dobson AP and others (2002) Microparasite transmission and persistence. In: Hudson PJ, Rizzoli A, Grenfell BT, Heesterbeek H, Dobson A (eds) The ecology of wildlife diseases. Oxford University Press, Oxford, p 83-101 